\title{
Mean Leeway space in Nepalese children attending a tertiary care hospital, Bhaktapur: A radiographic evaluation
}

\section{Pradhan $\mathrm{M}^{1}$, Dhital $\mathrm{S}^{2}$, Joshi $\mathrm{U}^{3}$, Poudyal $\mathrm{S}^{4}$}

${ }^{1}$ Megha Pradhan, Assistant Professor, ${ }^{2}$ Shweta Dhital, Lecturer, Department of Pedodontics and Preventive Dentistry; ${ }^{3}$ Ujjwal Joshi, Associate Professor, Department of Oral Medicine and Radiology, Kathmandu Medical College and Teaching Hospital; ${ }^{4}$ Sijan Poudyal, Associate Professor, Department of Community Dentistry, KIST Medical college and Teaching Hospital, Lalitpur, Nepal.

\begin{abstract}
Background: Leeway space becomes important during the change of dentition and occlusal development. Objectives: The study was designed to measure the mean leeway space of maxilla and mandible of Nepalese children using Orthopantomogram radiographs and also to compare the difference between mean leeway space in male and female children.

Methodology: After ethical approval, 270 OPG (Orthopantomogram) radiographs of age groups 6-12 years Nepalese children exhibiting mixed dentition were selected for the study after following the inclusion and exclusion criteria by convenience sampling method. A digital measurement in the OPG software was used to measure the mesiodistal width of deciduous canine and molars along with permanent canine and premolars in all quadrants.

Results: The mean leeway space on maxilla was seen to be $(0.86 \pm 1.97 \mathrm{~mm})$ while for mandible was $(2.45 \pm 1.85 \mathrm{~mm})$.The leeway space in both maxilla and mandible was seen to be more in females $(0.87 \pm 1.87 \mathrm{~mm})$ and $(2.52 \pm 1.85 \mathrm{~mm})$ than in males $(0.85 \pm 2 \mathrm{~mm})$ and $(2.40 \pm 1.90 \mathrm{~mm})$ respectively.

Conclusion: The mean leeway space in Nepalese children was found to be less than the standard "Leeway space of Nance" which could be due to population tooth crown differences and various environmental factors. Further studies could be recommended in the future both radiographically and clinically for obtaining a standardized leeway space for Nepalese population.
\end{abstract}

Key words: Dental occlusion; Leeway Space; Mixed dentition

DOI: https://doi.org/10.3126/jkmc.v8i4.32389

\section{INTRODUCTION}

Cuidance of eruption and development of the

$J$ primary, mixed, and permanent dentitions is an integral component of comprehensive oral health care for all pediatric dental patients'. Nance observed the combined mesiodistal width of permanent canine and premolars to be less than that of deciduous canine

Address for correspondence

Dr. Megha Pradhan,

Department of Pedodontics and Preventive Dentistry,

Kathmandu Medical College Teaching Hospital, Duwakot, Bhaktapur.

Email: drmeghapradhan@gmail.com

ORCID: Megha Pradhan: (0000-0003-3381-3342)

Shweta Dhital: (0000-0002-7786-9869)

Ujjwal Joshi: (0000-0003-3745-3794)

Sijan Poudyal: (0000-0001-5642-701X) and molars. The difference was observed to be $1.8 \mathrm{~mm}$ $(0.9 \mathrm{~mm}$ on each quadrant) in maxillary arch and $3.4 \mathrm{~mm}$ $(1.7 \mathrm{~mm}$ on each) in mandibular arch. Extra space is called Leeway Space of Nance and is utilized by mandibular molars to establish class I relationship through late mesial shift ${ }^{2}$. The control of leeway space in terms of arch dimensional changes through space supervision may offer opportunities to significantly improve tooth sizearch size adjustments for the relief of typical levels of crowding $^{3}$. The Leeway Space becomes important during the change of dentition and the occlusal development. Precise knowledge of the available Leeway Space forms the basis for decisions about possible orthodontic treatment. A common question/dilemma is whether there is enough space for all teeth or does one have to consider tooth extractions $s^{4}$. The previous studies on Leeway Space have been done in various population around the globe. The findings with respect to Nepalese 
population have not been extrapolated. Precision of the knowledge would enable the clinicians to make a sound decision on the space problems in Nepalese children. This study was designed to measure the mean leeway space of maxilla and mandible of Nepalese children using Orthopantomogram radiographs and to compare the difference between mean leeway space in male and female children of Nepal.

\section{METHODOLOGY}

A cross-sectional study was done in Department of Oral medicine and Radiology, Kathmandu Medical College and Teaching Hospital after getting clearance from institutional review committee of the same institution. The study was carried from October to November 2019.

The sample size calculation was done with the formula; $\mathrm{n}=$ (ts/ME), where standard deviation $(\mathrm{s})=0.2$ taken from previous study ${ }^{4}$, if we permit $0.02 \mathrm{~mm}$ error in leeway space with $90 \%$ confidence interval. In sample size calculation, since we are dealing with comparison of mean value of leeway space with population mean, we took formula $\mathrm{ME}=\mathrm{ts} / \sqrt{ } \mathrm{n}$. ME stands for margin of error, $\mathrm{t}$ value calculates the confidence interval and is dependent upon degree of freedom and desired confidence level. Since sample size is large that is more than $30, t$ value is close to $z$ value and here $90 \%$ confidence interval is 1.645 . So, the total sample $n=270$ was calculated. Convenience sampling technique was followed. Informed Consent was taken before commencement of the study. Orthopantomograms (OPG) of 6-12 yearold children taken for routine radiographic evaluation during dental consultation and fulfilling the inclusion criteria were selected for the study. The inclusion criteria for selection of the OPG was the presence of deciduous canine, first molar, second molar in all the quadrants with successors permanent canine, first premolar and second premolar.
OPG showing proximal caries on the deciduous canine and molar teeth, missing deciduous canine and molars teeth or permanent canine and premolar teeth, any pathology like cyst, tumors, defects of enamel or dentin and rotations, deformation of the involved deciduous teeth were excluded from the study.

Leeway space of maxilla and mandibles of 6-12 year old Nepalese children were measured and compared to see if any difference exists between genders. Panoramic radiographs were taken using Planmeca ProMax (Helsinki, Finland) under similar conditions (66 Kvp, 6 mA, 14 s). A metallic ball bearing was taken which was measured with digital Vernier caliper and found to be $10.3 \mathrm{~mm}$ in diameter. The ball bearing was placed on the dry mandible which was stabilized with modelling wax. The radiograph of dry mandible with ball bearing was taken with Planmeca Promax OPG machine and the radiographic image was analyzed with Planmeca Romexis Viewer 5.3.3.5. Digital measurement of radiographic image of ball bearing was done and the diameter was found to be $10.3 \mathrm{~mm}$. So, the magnification factor was calculated as 1 .

Planmeca Romexis Viewer 5.3.3.5 software was used to measure the mesiodistal width of deciduous canine and molars along with permanent canine and premolars in all quadrants. All the measurements of OPGs were performed by the same observer to avoid any error.

\section{RESULTS}

Out of the 270 OPG examined, males were 154 (57\%) while rest belonged to female. The mean leeway space on maxilla was seen to be $(0.86 \pm 1.97) \mathrm{mm}$ while for mandible was $(2.45 \pm 1.85) \mathrm{mm}$. The leeway space in both maxilla and mandible was seen to be more in females $(0.87 \pm 1.87)$ and $(2.52 \pm 1.85) \mathrm{mm}$ than in males $(0.85 \pm$ 2) $\mathrm{mm}$ and $(2.40 \pm 1.90) \mathrm{mm}$ respectively. (Table 1$)$

Table 1: Leeway space of maxilla and mandible

\begin{tabular}{lccccc} 
& \multicolumn{2}{c}{ Male $(\mathbf{n = 1 5 4 )}$} & & Female $(\mathbf{n = 1 1 6 )}$ & Total $(\mathbf{n}=\mathbf{2 7 0})$ \\
& Mean & Median & Mean & Median & \\
Maxilla $(\mathrm{mm})$ & $0.85 \pm 2$ & 1.1 & $0.87 \pm 1.87$ & 1.0 & $0.86 \pm 1.97$ \\
\hline Mandible $(\mathrm{mm})$ & $2.40 \pm 1.90$ & 2.7 & $2.52 \pm 1.85$ & 2.8 & $2.45 \pm 1.85$ \\
\hline
\end{tabular}




\section{DISCUSSION}

Clinical decisions are presented daily that challenge pediatric practitioners in affecting outcomes in management of the developing occlusion. The decision for managing space in the mixed dentition poses a dilemma to the practitioners and among them reliability on the leeway space is one of them.

This study showed mean leeway space on maxilla to be $(0.86 \pm 1.97) \mathrm{mm}$ while for mandible was $(2.45 \pm 1.85)$ $\mathrm{mm}$. These findings are less as compared to the findings given by Moyers ${ }^{5}$ where leeway space in maxilla was 2.6 $\mathrm{mm}$ and mandible was6.2 $\mathrm{mm}$ and Botero $\mathrm{P}$ et a ${ }^{6}$ where the maxillary leeway space was $1.55 \pm 2.64 \mathrm{~mm}$ and the mandibular space was $3.62 \pm 2.76 \mathrm{~mm}$.

The findings in this study fall within the variation of 0.7 to $1.5 \mathrm{~mm}$ in the maxilla and 1.7 to $3.3 \mathrm{~mm}$ in the mandible as suggested by various authors ${ }^{6}$.These range of variations could depend on regional or population tooth crown differences plus sampling variation ${ }^{7}$.The deciduous crowns mature perinatally ${ }^{8}$ depending mostly in the maternal physiology ${ }^{9}$ which remain same throughout the years but improvement in childhood nutrition ${ }^{10}$ in these days could promote the formation of larger postnatal permanent teeth ${ }^{11}$ leading to the differences in the deciduous and permanent tooth sizes.

This study showed leeway space in mandible to be more in females $(2.52 \pm 1.85) \mathrm{mm}$ than in males $(2.40 \pm 1.90)$ $\mathrm{mm}$, similar to studies done by Hille et al ${ }^{12}$. This finding also shows similarity to study by Tarvade et $\mathrm{al}^{4}$. Leeway space in mandibular arch is more critical. There are fewer therapeutic options in this arch because of its limited potential for expansion, unstable labialization of incisors and difficulty of molar distalization ${ }^{13}$.The Leeway Space becomes important during the change of dentition and the occlusal development. It can be utilized to solve the physiological crowding in the lower front area caused by the eruption of permanent incisors by preventing the mesial drift of the lower 1st molars by a lingual arch placed before the exfoliation of the 2nd primary lower molars. So, preservation of Leeway Space is necessary for gaining space for alignment in mixed dentition ${ }^{4}$.

Disadvantages of using panoramic radiograph are the unequal magnification and distortion that may occur when the patient's jaws are not positioned within the focal trough of the X-ray beam ${ }^{14}$. Even though precautions had been taken to minimize the unequal magnification and distortion, yet it is still undeniable that it didn't exist. Cone Beam Computed Tomography (CBCT )has been found to be the most accurate radiographic technique in measuring the tooth, root, and crown lengths than IOPAR (Intraoral Periapical Radiographs) and $\mathrm{OPG}^{15}$ which could highly influence the measurement of leeway space so, further studies could be planned on CBCT.

\section{CONCLUSION}

The mean leeway space in Nepalese children was found to be less than the standard "Leeway space of Nance" which could be due to population tooth crown differences and various environmental factors. Further studies could be recommended in future both radiographically and clinically for obtaining a standardized leeway space in Nepalese population.

6. Botero P, Ariza SG, Meneses D, Zapata E, Alvarez LG. Appraisal of the difference between the mesiodistal diameters of deciduous incisors and molars and permanent teeth.Eur J Paediatr Dent. 2015 Mar;16(1):39-44.[PubMed | FullText]

7. Buwembo W, Luboga S. Moyers' method of mixed dentition analysis: a meta-analysis. Afr Health Sci. 2004 Apr;4(1):63-6.[PubMed | FullText]

8. Hu X, Xu S, Lin C, Zhang L, Chen Y, Zhang Y. Precise chronology of differentiation of developing human primary dentition. Histochem Cell Biol. 2014 Feb;141(2):221-7.[PubMed | FullText | DOI]

9. Vail $B$, Prentice $P$, Dunger DB, Hughes IA, Acerini CL, Ong KK. Age at weaning and infant growth: primary analysis and systematic review. J Pediatr. 2015 Aug;167(2):317-24.[PubMed | FullText | DOI] 
10. Markel H, Golden J. Successes and missed opportunities in protecting our children's health: critical junctures in the history of children's health policy in the United States. Pediatrics. 2005 Apr; 115(4 Suppl):1129-33. [PubMed | DOI | FullText]

11. Martorell R. Physical growth and development of the malnourished child: contributions from 50 years of research at INCAP. Food Nutr Bull. 2010 Mar;31:68-82. [PubMed | DOI | FullText]

12. Hille HM. The Mean Leeway Space in a Population of Orthodontic Patients in Zürich. [dissertation]. College of Dentistry, University of Zürich, 2010. [FullText]
13. Vyas MB, Hantodkar N. Resolving mandibular arch discrepancy through utilization of leeway space. Contemp Clin Dent.2011 Apr-Jun;2:115-118. [PubMed | DOI | FullText]

14. Devlin H, Yuan J. Object position and image magnification in dental panoramic radiography: a theoretical analysis. Dentomaxillofac Radiol. 2013; 42(1): 29951683.[PubMed | DOI | FullText]

15. Adarsh K, Sharma P, Juneja A. Accuracy and reliability of tooth length measurements on conventional and CBCT images: An in vitro comparative study. J Orthodont Sci. 2018 Sept;7:17.[PubMed | DOI | FullText] 